\title{
Special Issue on Long-Term Care for Older Adults in East Asian Countries
}

Jae-Young Lim

Department of Rehabilitation Medicine, Seoul National University Bundang Hospital, Seoul National University College of Medicine, Seongnam, Korea

East Asian countries are the most rapidly aging regions in the world, as the life expectancies of their populations are relatively high. As long as longevity increases without a meaningful increase in health-adjusted life expectancy, the proportion of life spent in poor health and the number of older people living with disease and functional impairment is bound to increase. ${ }^{1)}$ This is a critical issue that threatens the sustainability of each society. Thus, it has been a high policy priority to develop long-term care systems separately from or integrated with the healthcare systems beyond medical care, including disease treatment and prevention. A long-term care system is defined as a system that enables older people experiencing significant declines in capacity to receive the care and support of others, consistent with their basic rights, fundamental freedoms, and human dignity. ${ }^{2)}$ Several countries have separate longterm care systems. In Japan, the most aged country in the world, the long-term care insurance system was initiated and established in 2000. It has been 12 years since the Korean government implemented a long-term care system incorporated with the National Health Insurance in 2008. In Taiwan, a variety of long-term care services have been provided to the public by the tax-funded system.

I am pleased to announce the release of a special issue in Annals of Geriatric Medicine and Research on the current status of longterm care services in East Asian countries. The purpose of this special issue is to provide an overview of long-term care services among neighboring countries with cultural similarities and similar population pyramids and to raise global interest in the role of longterm care systems. Representative geriatric and gerontologic experts from Korea, Japan, and Taiwan have contributed to describing the past, present, and future of long-term care systems. This special issue provides a glimpse into the legal considerations, institutional frameworks, financial resources, service content, limitations, and challenges of these systems. The circumstances faced by these countries may not be different from those of many other countries in the 21st century. This issue would be informative for those coping with ongoing problems threatening the health and welfare of older adults.

In the future, our journal will serve as a venue for sharing and introducing each other's experiences not only from these three countries, but also from other Asian countries expecting uprise of population aging. I hope that this initiative will help promote the building of a special interest group in the long-term care field and help keep this issue on the table.

\section{ACKNOWLEDGMENTS}

\section{CONFLICT OF INTEREST}

The author claims no conflicts of interest.

\section{REFERENCES}

1. Lim JY. What should geriatric medicine do in the new normal of life expectancy? Ann Geriatr Med Res 2018;22:1-2.

2. World Health Organization. Long-term-care systems [Internet]. Geneva, Switzerland: World Health Organization; c2020 [cited 2020 Sep 19]. Available from: https://www.who.int/ageing/ long-term-care/en/.

Corresponding Author: Jae-Young Lim, MD, PhD

Department of Rehabilitation Medicine, Seoul National University Bundang Hospital, Seoul National University College of Medicine, 82 Gumi-ro 173beon-gil, Bundang-gu, Seongnam 16320, Korea

E-mail: drlim1@snu.ac.kr

ORCID: https://orcid.org/0000-0002-9454-0344

Received: September 19, 2020; Accepted: September 20, 2020 